\title{
A Simple Cyclic Falling-Film Molecular Still
}

\author{
By John Keenan Taylor
}

\begin{abstract}
The efficient cyclic falling-film molecular still described is characterized by simplicity of operation and ease of construction. The liquid to be distilled is pumped from the reservoir and introduced on the vertical cylindrical evaporator by an annular orifice. The resulting uniform distribution of the distilland, together with the short column used, makes for efficient operation. The apparatus may be used for charges of liquid ranging from a minimum of about $10 \mathrm{ml}$ to 1 liter or more.
\end{abstract}

\section{Introduction}

Molecular distillation is becoming of increasing interest for the separation and purification of many kinds of materials. For example, the process makes possible the separation of constituents of natural oils, fats, and waxes which have formerly been considered undistillable. $[5,6]^{*} \mathrm{~A}$ number of stills have been described in the literature for utilizing this method, ranging in size from those intended for handling a few drops of material to those capable of dealing with tankcar quantities. When small volumes of material are involved, of the order of a few milliliters or less, the experimenter is limited to the comparatively inefficient pot still. When larger amounts are at hand, cyclic falling-film stills are much to be preferred.

It has been emphasized $[2,4,6,8]$ that molecular distillation, or free evaporation as it is also called, takes place only from an extremely thin surface layer of the distilland. Hence, it is of utmost importance that this layer at all times be representative of the bulk of the liquid. The surface is being continually impoverished by preferential escape of the more volatile components, so that some means of maintaining the equilibrium between bulk and surface concentration must be provided. In pot stills convection and diffusion

*Figures in brackets indicate literature references at the end of this paper. are depended upon to renew the surface, and the ineffectiveness of these processes at high rates of distillation is reflected in the inefficiency of the apparatus. For this reason, stills in which a thin film of distilland is flowed over a heated surface, so that the distilling layer is chiefly the entire bulk of the liquid, have supplanted the older pot type wherever practicable. The film still has the added advantage of minimizing the time that the liquid is held at an elevated temperature, which is a very important consideration when dealing with thermally unstable materials.

The chief problem involved in the design of falling-film stills is to provide for uniform distribution of the distilland on the surface of the evaporator. Failure to do so results in preferential distillation of the more readily heated thinner layers, and consequently a tendency to approach bulk distillation rather than surface evaporation. A number of devices have been suggested to overcome this difficulty. These have consisted of embossed designs on the surface of the evapora-

\section{Contents}

I. Introduction Page

II. Description of apparatus__._. 174

III. Method of operation

IV. References. 
tor [6], cascade dividers [1], rotating distributors [7], coating the column with ground glass [3], and like measures. One group of investigators made use of a serrated distributor at the top of the column and a wire wound spirally around the column to facilitate the distribution of the liquid [9]. Detwiler and Markley [3] claim good results by admitting the distilland at the top of the column by means of a tapered sleeve guide, by providing a mushroom head at the top of the column, and coating the entire evaporator with fragmented glass. On the mechanical side, Quackenbush and Steenbock [10] have described a still in which a magnetically operated rotor continually wipes the evaporating film. The highly efficient but complicated rotary-film stills of Hickman [6] may be considered as the ultimate in design for minimizing the difficulties inherent in the distribution of the distilland.

Most of the devices suggested to increase the efficiency of molecular stills appear to be either of doubtful value or else require cumbersome and expensive mechanical equipment for their utilization. The still described in this paper achieves excellent distribution of the evaporating film by a simple and easily constructed device. In addition, it incorporates some of the best features of those already described.

\section{Description of Apparatus}

The features of design that have been aimed for in this still are [a] excellent distribution of distilling layer of liquid, [b] a short column to minimize impoverishment of the distilling surface, and [c] high ratio of rate of renewal of surface to rate of distillation. The apparatus is shown diagramatically in figure 1 . The still proper is indicated by $M$. It consists of a central evapora-

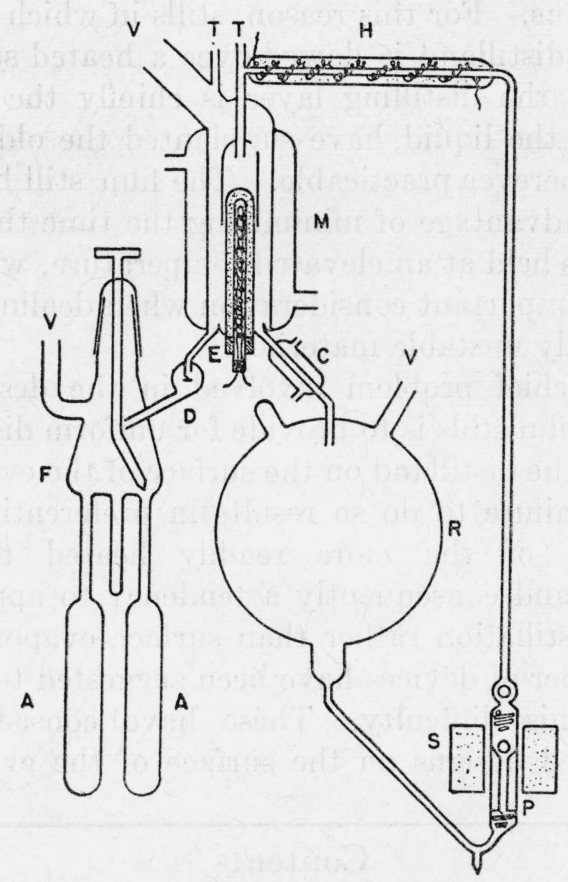

FIGURe 1.-Molecular still

$A$, Ampoules; $C$, cooler; $D$, drop counter; $E$, evaporator; $F$, fraction collector; $H$, preheater; $P$, pump; $R$, reservoir; $S$, solenoid; $T$, thermocouple outlets; $V$, vacuum leads. tor, $E$, surrounded by a condensing surface. The distinctive feature of the apparatus is the system for distributing the liquid upon the surface of the evaporator. A tube of internal diameter slightly larger than the outside diameter of the evaporator is placed over the top portion of it so that an annular orifice of uniform dimensions is formed. The operation is as follows. As the liquid is pumped into this distributor, a head is built up until the integrated rate of flow from the orifice equals the delivery rate of the pump. In practice, a head of about 1 to $2 \mathrm{~cm}$ is maintained so that a continuous supply of liquid to the evaporator is assured. When carefully constructed, this annulus produces a film which starts uniformly around the entire surface of the evaporator and which persists as it falls.

Since the apparatus should prove useful for a number of applications, the details of its construction will be given. Evaporator, $E$, is made from a glass tube $18 \mathrm{~mm}$ in diameter ${ }^{1}$ the outside surface of which had been finely ground to facilitate the distribution of the liquid. A heater of nichrome wire contained in a $7-\mathrm{mm}$ tube is placed in the center, and the space between it and the walls of the evaporator is filled with 2-mm lengths of bare copper wire to facilitate heat distribution. The "bonnet" for distributing the liquid on the column is of $22-\mathrm{mm}$ tubing ( $19-\mathrm{mm} \mathrm{i}$. d.) so that an annulus of about $0.5-\mathrm{mm}$ width is formed. A metal shim, which was subsequently dissolved in

1 The apparatus is constructed of ordinary Pyrex glass tubing of standard wall thickness. All sizes are the nominal outside dimension unless otherwise stated. 
acid, served to space this tube during the fabrication. The bonnet extends for a distance of about $15 \mathrm{~mm}$ over the evaporator, there being exposed a $60-\mathrm{mm}$ length of evaporating surface. The shortness of the evaporator follows the recommendation of Fawcett [4], who showed that long columns have a decreased efficiency.

The concentric condenser, surrounded by a water jacket, is of $45-\mathrm{mm}$ tubing. The minimum vapor path between the evaporator and condenser is thus about $12 \mathrm{~mm}$. A vacuum lead of $20-\mathrm{mm}$ tubing is ample to remove residual gas and decomposition products formed during the distillation.

The bottom of the still is arranged with two concentric gutters that carry distillate to fraction collector, $F$, and residue to reservoir, $R$, respectively.

Thermocouples are inserted at $T$ to measure the temperature of the incoming liquid and also to measure the temperature of the falling film, if so desired. A thermocouple inserted at the copperglass interface in $E$ measures the temperature of the evaporator.

A cooler, $C$, may be used to cool the liquid as it leaves the still and enters the reservoir, if this is desirable. The reservoir, $R$, is made from a round-bottom flask of one liter capacity. ${ }^{2}$ It is provided with a vacuum lead, $V$, and a tube for the introduction of the material to be distilled. A male standard-taper ground joint sealed to $R$, near the top, and normally closed with its female complement offers a convenient means for introducing samples without danger of contamination with stop-cock grease. (This arrangement is not shown in the figure.) An electric heater may also be placed around the bottom of $R$ to assist in the preliminary degassing of the liquid.

The pump circulates liquid from $R$ to the still. It consists of a solenoid-operated hollow piston, $P$, of steel with a bronze-ball lift valve seating on its conical surface. The diameter of the piston is chosen so that a reasonably close fit with the body of the pump is obtained. A tight fit is neither necessary nor desirable. Only a slight loss of pumping efficiency results from a loose fit, while a

\footnotetext{
2 Some advantage is gained by using a smaller vesssel when dealing with small quantities. In either case the entrance tube leading in from the still should be placed so that it is directed toward the exit sump of the reservoir to decrease the drainage hold-up for small volumes of liquid.
}

means to drain the apparatus is gained. Lifting the steel-ball check valve with a magnet also aids the drainage operation. A steel ball on a groundglass seat acts as a check valve. These metal parts are gold-plated to minimize corrosion. Nichrome wire springs inserted above and below the piston serve to protect the glass walls of the pump in the event of faulty operation. The glass body of the pump is made from 10-mm tubing, and its overall length is about $10 \mathrm{~cm}$. The tubes leading to and from the pump are 4-mm in diameter. By keeping these parts small, the minimum operating volume is about $10 \mathrm{ml} .^{3}$

The solenoid, $S$, contains 4,000 turns of No. 24 enameled, cotton-covered wire on a suitable brass spool enclosed in a case with steel ends and outer shell. The solenoid operates, in series with a suitable resistance, on the $115-\mathrm{v} d-\mathrm{c}$ line and is actuated by a relay controlled by an electronic impulse timer previously described [11]. By regulating the length of stroke, governed by the current in the solenoid, and the rate of pulsing, the pumping rate can be readily adjusted and controlled.

The sample collector, $F$, is similar to one described by Waddle [12]. It is constructed from a 125-ml Erlenmeyer flask to which is sealed a 19/38 standard-taper joint, as shown in the figure. This joint may be rotated to permit distillate to collect in any one of the four or five ampoules sealed to the bottom of the flask. A vacuum lead, $V$, is provided to assist in the evacuation of the apparatus.

The entire apparatus is mounted on a frame 15 inches wide and 30 inches high. The leads, $V$, are joined to a common tube which is in turn sealed to a conventional portable vacuum system consisting of fore vacuum pump, diffusion pump, traps, and MacLeod gage, all mounted on a frame of dimensions similar to those of the still. By cutting the one connecting lead, the two units may be easily transported to various locations in the laboratory.

\footnotetext{
3 Pumps operating in high vacuum are either lift or force pumps, and hydrostatic head of liquid above the check valve is the factor that replenishes the chamber of the pump. The minimum operating volume of the pump includes the volume contained in the lead tube up to the level of the check valve, the volume of the pump chamber, and the volume of liquid contained in the tube leading from the pump to the still proper. This, together with the drainage of the still and reservoir, constitutes the hold-up of the apparatus. The dimensions of the pump and tubes must be kept small to minimize this hold-up. Lift pumps, such as the one used here, appear to offer the greatest possibilities for combining the opposing characteristics of low hold-up and large pumping capacity.
} 


\section{Method of Operation}

The method of operation is essentially as follows. The liquid to be distilled is placed in $R$ and the introduction tube sealed or closed off with a ground joint. The system is then evacuated during which, at first, large quantities of dissolved gas are liberated. Reservoir, $R$, may be warmed with the heater provided for this purpose, to help remove gas. When evolution of gas ceases or slows down, the pump is operated, and the liquid is allowed to flow over the cold surface of the evaporator. Usually only a few cycles of flow are required to produce a perfectly quiet distillation. Warming the evaporator to a temperature that is insufficient to cause appreciable distillation greatly facilitates the degassing process.

The distillation is started when the pressure of the system reaches $10^{-4} \mathrm{~mm}$ of mercury or lower. The heater imbedded in the evaporator and the one located at $H$ are connected to adjustable voltage transformers and regulated so that the temperature of the incoming liquid is about equal to that of the evaporator. The pumping rate is adjusted so that approximately $1 \mathrm{ml} / \mathrm{sec}$ is circulated around the system. A high ratio of rate of flow to rate of distillation is desirable, as under this condition of operation, the chance for formation of stagnant layers of distilland on the surface of the evaporator is decreased. The distillate is collected in suitable fractions in the ampoules, $A$, sealed to $E$. At the end of the distillation, the residue containing the less volatile components is removed at the breakoff tip drain shown near the bottom of the pump.

\section{References}

[1] F. E. Bancroft, British Patent 428,719 (May 15, 1935).

[2] G. Burrows, J. Soc. Chem. Ind. 58, 50-56 (1939).

[3] S. B. Detwiler, Jr. and K. S. Markley, Ind. Eng. Chem. Anal. Ed. 12, 348 (1940).

[4] E. W. Fawcett, J. Soc. Chem. Ind. 58, 43-50 (1939).

[5] K. C. D. Hickman, American Scientist 33, 205-31 (1945).

[6] K. C. D. Hickman, Chem. Rev. 34, 51-105 (1944).

[7] K. C. D. Hickman, U. S. Patent 2,249,526 (July 15, 1941).

[8] D. D. Howat, Chem. Age (London) 45, 309 (1941);
45, 323 (1941); 46, 3 and 41 (1941).

[9] W. Jewel, T. H. Mead, and J. W. Phipps, J. Soc. Chem. Ind., 58, 56-64 (1939).

[10] F. W. Quackenbush and H. Steenbock, Ind. Eng. Chem. Anal. Ed. 15, 468-70 (1943).

[11] J. K. Taylor and J. G. Reid, Jr., Ind. Eng. Chem. Anal. Ed. 18, 79 (1946).

[12] H. M. Waddle, Ind. Eng. Chem. Anal. Ed. 16, 537 (1944).

Washington, May 17, 1946. 